\title{
The effectiveness of home-use photobiomodulation toothbrush for treating dentin hypersensitivity: A pilot study
}

\author{
Maziar Mir ${ }^{1}$, Seyed Masoud Mojahedi ${ }^{2}$, Jan Tunér ${ }^{3}$, Masoud Shabani ${ }^{4 *}$, \\ Fatemeh Darabi ${ }^{5}$, Alireza Rohban ${ }^{6}$
}

1: DDS, MSc.Alumnus, RWTH Hospital, Aachen, Germany.Mir.maziar@gmail.com 2: DDS, Ph.D. Department of Laser, School of Dentistry, Shabid Beheshti University of Medical Sciences, Tehran,Iran.Seyed220@gmail.com

3: DDS, PhotoBioModulation Consultant, Sollentuna, Sweden.Tuner.jan@gmail.com 4: DDS, MSc. Department of Community Dentistry, School of Dentistry, Ardabil University of Medical Sciences, Ardabil,Iran.m.shabani@arums.ac.ir

5: Ph.D. Department of Public Health, Asadabad School of Medical Sciences, Asadabad, Iran.Fatemedarabi43@yaboo.com

6: M.Sc. Department of Rehabilitation Management, School of Rehabilitation Sciences, Iran University of Medical Sciences, Tehran, Iran.Rohban.a@gmail.com.

\begin{abstract}
Background and Aims: Dentin hypersensitivity is a frequent oral condition among patients suffering from gingival recession. Recent studies have suggested that photobiomodulation has the potential to reduce inflammation and relieve pain. The present study aims to assess the effectiveness of a new design of photobiomodulation toothbrush with specific irradiation parameters as a homecare device in treating dentin hypersensitivity and to compare its therapeutic effect with that of fluoride varnish.

Materials and Methods: Thirty patients with gingival recession and dentin hypersensitivity were selected and randomly assigned to three groups of equal size: fluoride varnish, photobiomodulation, and the combination. Dentin pain and hypersensitivity were measured using visual analog scale (VAS) by two distinct tests: the contact test with a periodontal probe and the air blast test on the areas of gingival recession and denuded root; once at baseline and again one month after the initial application of treatments. Laser irradiation was carried out at the wavelength of $660 \mathrm{~nm}$ in CW with an output power of 40 $\mathrm{mW}$ for 30 seconds per spot $\left(1.2 \mathrm{~J}\right.$ per spot, $6 \mathrm{~J} / \mathrm{cm}^{2}$ energy density, and $200 \mathrm{~mW} / \mathrm{cm}^{2}$ power density), perpendicularly to denuded root surfaces in non-contact mode.

Results: A significant reduction in dentin pain and hypersensitivity was observed in all three groups. However, the reduction was significantly greater in the combination group.

Conclusion: At-home treatment of dentin hypersensitivity with photobiomodulation toothbrush is a convenient, safe, and effective method for the management of dentin hypersensitivity.
\end{abstract}

Key words: Dentin hypersensitivity $\cdot$ photobiomodulation $\cdot$ fluoride varnish

\section{Introduction}

Dentin hypersensitivity (DH) is a common dental problem among patients with gingival recession ${ }^{1,2)}$. DH is characterized by a short and sharp pain evoked by different mechanical, chemical, and thermal stimuli ${ }^{3,4}$. Various

\footnotetext{
*Addressee for Correspondence:

Masoud Shabani

Department of Community Dentistry, School of Dentistry,

Ardabil University of Medical Sciences, Ardabil, Iran.

Email; m.shabani@arums.ac.ir,

Tel: +989141511477, Fax: +9845-33521800

treatment techniques such as high-intensity laser therapy (HILT) and photobiomodulation (PBM) have been proposed in an attempt to alleviate the problem ${ }^{5,6}$. Diode lasers have a wide range of applications in dentistry thanks to their low prices and small size as well as their power to generate a variety of wavelengths both in visible and near infrared portions of the spectrum ${ }^{77}$. These lasers are used to relieve pain, accelerate healing, and reduce inflammation in many oral problems ${ }^{8-10)}$. To achieve

Received date: February 21st, 2019 Accepted date: May 21st, 2019 
the best results, it is necessary to identify optimal laser parameters specific to the problem ${ }^{11,12)}$. PBM is commonly used in dental clinics to alleviate pain and DH. However, it requires patients to visit the clinic frequently. The present study aims to assess the effectiveness of a new design of PBM toothbrush with specific irradiation parameters as a homecare device in treating dentin hypersensitivity and to compare its therapeutic effect with that of fluoride varnish.

\section{Materials and methods}

Thirty patients with denuded roots and DH (15 males and 15 females) who were referred to a private dental clinic in Ardabil city, Iran, were included in the study. The inclusion criteria were (1) existence of at least one tooth with gingival recession of $1-2 \mathrm{~mm}$; (2) DH in lower incisor teeth; and (3) patients' willingness to participate. On the other hand, the exclusion criteria were (1) pregnancy; (2) breastfeeding; (3) widely filled teeth in which the treatment has reached the recession zone; (4) para-functional habits; (5) orthodontic treatment; (6) history of using anti-DH agents in the last month; (7) history of tooth bleaching in the last four months; (8) eating disorders such as bulimia; (9) gastroesophageal reflux disease; (10) cracked or broken tooth; (11) tooth decay; (12) root canal treated tooth; (13) root end damaged tooth; (14) carcinoma; (15) use of steroids and/or anticoagulants; (16) mental retardation or other disabilities; (17) frequent consumption of acidic beverage; (18) incomplete treatment of teeth in the last three months; and (19) plaque control index lower than $80 \%$ after oral care education. The subjects were randomly selected and assigned to three groups of equal size; (1) fluoride varnish; (2) PBM toothbrush; and (3) the combination.

\section{(1) Fluoride Varnish}

The sensitive teeth were treated with 5\% sodium fluoride varnish Preventa (Aria Dent, Asia Chimi Co., Tehran, Iran) in the dental clinic five times every five days. Initially, the subjects were asked to clean their teeth by brushing and flossing carefully. Then, their plaque control index was recorded. After ensuring that there is no plaque or debris left on the teeth, the varnish mixture was homogenized according to the manufacturer's instruction. Then, the teeth were isolated and dried with compressed air, and were covered with a thin layer of varnish whereby the denuded root surfaces and teeth were treated. The subjects were asked to abstain from eating and drinking for two hours, as well as from brushing or flossing until the next morning so that more fluoride could be absorbed with a longer contact time ${ }^{13}$.

\section{(2) PBM toothbrush}

The sensitive teeth were irradiated at home by patients using PBM toothbrush, twice a day (in the morning and evening after routine tooth brushing), and three times per week, for a month. The patients were instructed on how to use the toothbrush with safety goggles to be protected against irradiation (Laserpair, Shenzhen, China). For this group, the sensitive teeth were not treated with fluoride varnish. Laser irradiation had the following specifications: wavelength of $660 \mathrm{~nm}$, output power of $40 \mathrm{~mW}$, spot size of $0.2 \mathrm{~cm}^{2}$, continuous, non-contact with $5 \mathrm{~mm}$ distance from the irradiation area, and perpendicular to the target area. The laser irradiation parameters were: $1.2 \mathrm{~J}$ per spot, $6 \mathrm{~J} / \mathrm{cm}^{2}$ energy density, and $200 \mathrm{~mW} / \mathrm{cm}^{2}$ power density. Every denuded area was irradiated for 30 seconds (Figure 1). The output power of the laser was confirmed by the Laser and Plasma Research Institute of Shahid Beheshti University, Tehran, Iran. Further, the patent was registered at the Iran Intellectual Property Center under the code IR: 72619.

\section{(3) Combination}

Both treatment techniques were performed for the sensitive teeth in the same procedure as that for groups 1 and 2. First, the sensitive teeth were treated with PBM toothbrush at home by patients, twice a day (in the morning and evening after routine tooth brushing), and three times per week, for a month. Then, the sensitive teeth were treated with $5 \%$ sodium fluoride varnish in dental clinic five times, every five days.

Dentin pain and hypersensitivity were recorded using the WHO/Community Periodontal Index of Treatment Need (CPITN) by the contact test which measured the pain and sensitivity with a $0.5 \mathrm{~mm}$ diameter ball end. The cold

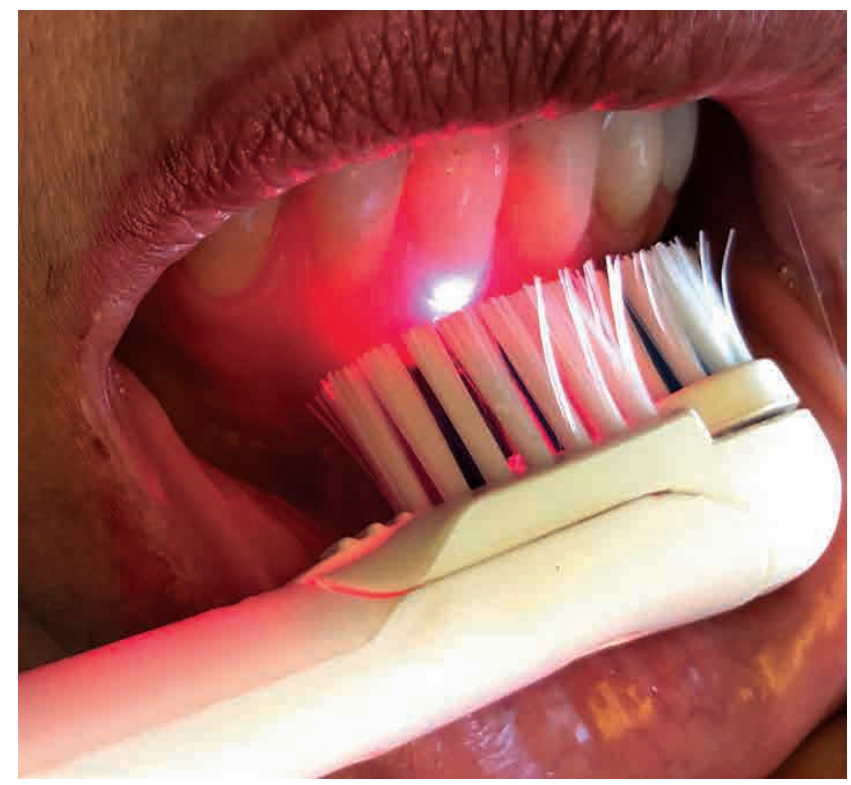

Figure 1: An illustration of how PBM toothbrush targets the hypersensitive areas 
sensitivity was measured by the air blast test. The denuded root surfaces were exposed to cold air blast in order to record the pain and sensitivity using VAS method within a range from 0 to 10, with 0 indicating "no pain" and 10 indicating "worst imaginable pain." Data were recorded in a questionnaire and analyzed by SPSS ver. 16 software.

\section{Ethical consideration}

This study was registered in the Iranian Registry of Clinical Trials (registration number IRCT2013061113639N1). Approval to use the PBM toothbrush was issued by the Ethics Committee of Ardabil University of Medical Sciences (approval number ARUMS: Rec. 1391.1023). Before the study, all patients were provided with a brief explanation of the purpose and procedure, as well as the possible risks of the study. Informed consent was obtained from all of the participants. In addition, the same brand of toothpaste (Nasim toothpaste, Paxan Co., Tehran, Iran), without desensitizing agents, was used by all participants.

\section{Results}

The mean microbial plaque index at baseline in groups 1 , 2 , and 3 was 14.1, 14.4, and 13.4, respectively. However, one month after the intervention, it was significantly reduced to 10.9, 10.3, and 9.9, respectively. The mean VAS score obtained by the air blast test at baseline in groups 1 , 2 , and 3 was 8.2, 7.9, and 8.3, respectively. However, one month after the intervention, it significantly diminished to 2.1, 2.4, and 0.8, respectively ( $\mathrm{p}=0.001)$ (Table 1). The contact test revealed that the mean VAS score in groups 1 , 2 , and 3 significantly dropped from 8.2, 8.0, and 8.5 at baseline to 2.6, 2.2, and 1.0 one month after the intervention ( $\mathrm{p}=0.001)$ (Table 2). All treatment modalities provided significant overall relief in pain and hypersensitivity. On the other hand, more significant relief was observed in participants who applied both PBM toothbrush and fluoride varnish (Table 3-1, Table 3-2). Note that we did not observe any side effects and allergy during and after the intervention. Additionally, none of the patients reported any complaints associated with the treatments either.

\section{Discussion}

Different treatment techniques have been proposed to treat $\mathrm{DH}$, most of which target dentinal pulp tissues and closure of dentinal tubules. Examples include the use of fluoride or potassium nitrate-containing toothpaste for athome treatments as well as application of fluoride varnish, glutaraldehyde, bonding agents, sealants, oxalates, and laser in dental clinics ${ }^{14,15)}$. Fluoride varnish can form a protective layer of calcium fluoride to reduce fluid movements inside the dentinal tubules to relieve pain ${ }^{16)}$. PBM can alleviate pain and $\mathrm{DH}^{17-19)}$ and help to treat other intraoral problems such as HSV-1 ${ }^{20)}$, aphthae ${ }^{21)}$, and periodontal inflammation ${ }^{22}$. PBM induces changes in the neural transmission network within the dental pulp, particularly denuded dentin surfaces, and stimulate the production of secondary dentin. This mechanism narrows the occlusion of dentinal tubules openings and accelerates the release of endorphins from the synapses of nerve terminals located in the dentinal tubules ${ }^{3)}$.

Dantas et al. ${ }^{23)}$ reported that individual use of fluoride varnish or PBM could substantially reduce dentin pain and hypersensitivity among patients; however, fluoride varnish outperformed PBM within a short time. In contrast, several studies have indicated that PBM was more effective than fluoride varnish ${ }^{24-27)}$. For instance, Doshi et al. ${ }^{25)}$ noted that the application of PBM after periodontal operations could help to relieve pain and reduce DH. Pesevska et al. ${ }^{28)}$ reported similar findings regarding the favorable effects of PBM on pain reduction

Table 1 : The mean VAS score obtained by air blast test at baseline and one month after the intervention (N=30)

\begin{tabular}{lccc}
\multicolumn{1}{c}{ Group } & Baseline $(\mathrm{M} \pm \mathrm{SD})$ & After the intervention & Sig. (2-tailed) \\
\hline 1. Flouride Varnish & $8.2 \pm 1.37$ & 2.1 & 0.001 \\
\hline 2. PBM toothbrush & $7.9 \pm 1.58$ & 2.4 & 0.001 \\
\hline 3. Combination & $8.3 \pm 0.52$ & 0.8 & 0.001 \\
\hline
\end{tabular}

Table 2 : The mean VAS score obtained by contact test at baseline and one month after the intervention $(\mathrm{N}=30)$

\begin{tabular}{lccc}
\hline \multicolumn{1}{c}{ Group } & Baseline $\mathrm{M} \pm \mathrm{SD}$ & After the intervention & Sig. (2-tailed) \\
\hline 1. Flouride Varnish & $8.2 \pm 1.17$ & 2.6 & 0.001 \\
\hline 2. PBM toothbrush & $8.0 \pm 1.13$ & 2.2 & 0.001 \\
\hline 3. Combination & $8.5 \pm 1.26$ & 1.0 & 0.001 \\
\hline
\end{tabular}


following scaling and root planing. In a clinical trial by Ko et al. ${ }^{26)}$, the application of PBM toothbrush with a wavelength of $635 \mathrm{~nm}$ and output power of $6 \mathrm{~mW}$ was shown to be highly effective in reducing dentin pain and hypersensitivity.

Further, Yaghini et al. ${ }^{27)}$ observed a significant difference between the effectiveness of PBM toothbrush with a wavelength of $650 \mathrm{~nm}$ and output power of $5 \mathrm{~mW}$ and a conventional toothbrush in alleviating dentin pain and hypersensitivity. The laser used for the present investigation had a far higher output power and shorter irradiation time compared to those used by Ko et al. and Yaghini et al. ${ }^{26,27)}$. The optimal parameters for this device need to be adjusted over time, and further investigations are required to determine the best energy and duration for achieving the highest performance. The PBM toothbrush would be a better choice than hand-held PBM device since it is less expensive and more convenient. Easy application of PBM toothbrush at home along with a regular tooth brushing is another advantage. In addition, the design of light transmission from the source to the target site has considerably reduced the price of the toothbrush.

\section{Conclusion}

Patients with hypersensitivity can benefit from both PBM toothbrush and fluoride varnish; however, the combination of both treatments is more effective compared with using either of them alone. Due to the high efficiency and lack of apparent side effects and risks, the PBM toothbrush can be applied as a home care device by patients with $\mathrm{DH}$.

Table 3-1: Results of between-group comparisons based on analysis of variance and Fisher's least significant difference test

\begin{tabular}{|c|c|c|c|c|c|c|c|}
\hline \multirow{2}{*}{$\begin{array}{l}\text { Dependent } \\
\text { variable }\end{array}$} & \multirow{2}{*}{ Group } & \multirow{2}{*}{ Group } & \multirow{2}{*}{$\begin{array}{l}\text { Mean differ- } \\
\text { ence (I-J) }\end{array}$} & \multirow{2}{*}{ Std. error } & \multirow{2}{*}{ Sig. } & \multicolumn{2}{|c|}{ 95\% Confidence Interval } \\
\hline & & & & & & Lower bound & Upper bound \\
\hline \multirow{6}{*}{ VAS-con-b } & \multirow[t]{2}{*}{$\mathrm{FV}$} & PBM & .20000 & .32318 & .541 & -.4631 & .8631 \\
\hline & & Combination & -.30000 & .32318 & .361 & -.9631 & .3631 \\
\hline & \multirow[t]{2}{*}{ PBM } & $\mathrm{FV}$ & -.20000 & .32318 & .541 & -.8631 & .4631 \\
\hline & & Combination & -.50000 & .32318 & .133 & -1.1631 & .1631 \\
\hline & \multirow[t]{2}{*}{ Combination } & $\mathrm{FV}$ & .30000 & .32318 & .361 & -.3631 & .9631 \\
\hline & & PBM & .50000 & .32318 & .133 & -.1631 & 1.1631 \\
\hline \multirow{6}{*}{ VAS-con-1m } & \multirow[t]{2}{*}{$\mathrm{FV}$} & PBM & .40000 & .36515 & .283 & -.3492 & 1.1492 \\
\hline & & Combination & $1.60000^{*}$ & .36515 & .000 & .8508 & 2.3492 \\
\hline & \multirow[t]{2}{*}{ PBM } & $\mathrm{FV}$ & -.40000 & .36515 & .283 & -1.1492 & .3492 \\
\hline & & Combination & $1.20000^{*}$ & .36515 & .003 & .4508 & 1.9492 \\
\hline & \multirow[t]{2}{*}{ Combination } & $\mathrm{FV}$ & $-1.60000^{*}$ & .36515 & .000 & -2.3492 & -.8508 \\
\hline & & PBM & $-1.20000^{*}$ & .36515 & .003 & -1.9492 & -.4508 \\
\hline \multirow{6}{*}{ VAS-blast-b } & \multirow[t]{2}{*}{$\mathrm{FV}$} & PBM & .30000 & .37118 & .426 & -.4616 & 1.0616 \\
\hline & & Combination & -.10000 & .37118 & .790 & -.8616 & .6616 \\
\hline & \multirow[t]{2}{*}{ PBM } & $\mathrm{FV}$ & -.30000 & .37118 & .426 & -1.0616 & .4616 \\
\hline & & Combination & -.40000 & .37118 & .291 & -1.1616 & .3616 \\
\hline & \multirow[t]{2}{*}{ Combination } & $\mathrm{FV}$ & .10000 & .37118 & .790 & -.6616 & .8616 \\
\hline & & PBM & .40000 & .37118 & .291 & -.3616 & 1.1616 \\
\hline \multirow{6}{*}{ VAS-blast-1m } & \multirow[t]{2}{*}{$\mathrm{FV}$} & PBM & -.30000 & .39347 & .452 & -1.1073 & .5073 \\
\hline & & Combination & $1.30000^{*}$ & .39347 & .003 & .4927 & 2.1073 \\
\hline & \multirow[t]{2}{*}{ PBM } & $\mathrm{FV}$ & .30000 & .39347 & .452 & -.5073 & 1.1073 \\
\hline & & Combination & $1.60000^{*}$ & .39347 & .000 & .7927 & 2.4073 \\
\hline & \multirow[t]{2}{*}{ Combination } & $\mathrm{FV}$ & $-1.30000^{*}$ & .39347 & .003 & -2.1073 & -.4927 \\
\hline & & PBM & $-1.60000^{*}$ & .39347 & .000 & -2.4073 & -.7927 \\
\hline
\end{tabular}


Table 3-2: Results of between-group comparisons based on analysis of variance and Fisher's least significant difference test

\begin{tabular}{|c|c|c|c|c|c|c|c|}
\hline \multirow{2}{*}{$\begin{array}{l}\text { Dependent } \\
\text { variable }\end{array}$} & \multirow{2}{*}{ Group } & \multirow{2}{*}{ Group } & \multirow{2}{*}{$\begin{array}{l}\text { Mean differ- } \\
\text { ence (I-J) }\end{array}$} & \multirow{2}{*}{ Std. error } & \multirow{2}{*}{ Sig. } & \multicolumn{2}{|c|}{ 95\% Confidence Interval } \\
\hline & & & & & & Lower bound & Upper bound \\
\hline \multirow{6}{*}{ PI-b } & \multirow[t]{2}{*}{$\mathrm{FV}$} & PBM & -.30000 & 1.08764 & .785 & -2.5317 & 1.9317 \\
\hline & & Combination & .70000 & 1.08764 & .525 & -1.5317 & 2.9317 \\
\hline & \multirow[t]{2}{*}{ PBM } & $\mathrm{FV}$ & .30000 & 1.08764 & .785 & -1.9317 & 2.5317 \\
\hline & & Combination & 1.00000 & 1.08764 & .366 & -1.2317 & 3.2317 \\
\hline & \multirow[t]{2}{*}{ Combination } & FV & -.70000 & 1.08764 & .525 & -2.9317 & 1.5317 \\
\hline & & PBM & -1.00000 & 1.08764 & .366 & -3.2317 & 1.2317 \\
\hline \multirow{6}{*}{ PI-1m } & \multirow[t]{2}{*}{$\mathrm{FV}$} & PBM & .60000 & .36413 & .111 & -.1471 & 1.3471 \\
\hline & & Combination & $1.00000^{*}$ & .36413 & .011 & .2529 & 1.7471 \\
\hline & \multirow[t]{2}{*}{ PBM } & $\mathrm{FV}$ & -.60000 & .36413 & .111 & -1.3471 & .1471 \\
\hline & & Combination & .40000 & .36413 & .282 & -.3471 & 1.1471 \\
\hline & \multirow[t]{2}{*}{ Combination } & $\mathrm{FV}$ & $-1.00000^{*}$ & .36413 & .011 & -1.7471 & -.2529 \\
\hline & & PBM & -.40000 & .36413 & .282 & -1.1471 & .3471 \\
\hline
\end{tabular}

* The mean difference is significant at 0.05 levels.

Abbreviations: VAS-con-b = VAS score obtained by contact test at baseline

VAS-con-1m = VAS score obtained by contact test one month after the intervention

VAS-blast-b = VAS score obtained by air blast test at baseline

VAS-blast- $1 \mathrm{~m}=$ VAS score obtained by air blast test one month after the intervention

$\mathrm{PI}-\mathrm{b}=$ Plaque Index at baseline

$\mathrm{PI}-1 \mathrm{~m}=$ Plaque Index one month after the intervention

$\mathrm{PBM}=$ Photobiomodulation toothbrush

$\mathrm{FV}=$ Fluoride Varnish

Combination $=$ Photobiomodulation toothbrush + fluoride varnish

\section{References}

1: Cunha-Cruz J, Wataha JC, Heaton LJ, Rothen M, Sobieraj M, et al. The prevalence of dentin hypersensitivity in general dental practices in the northwest United States. The Journal of the American Dental Association. 2013;144(3):288-96.

2: Cartwright R. Dentinal hypersensitivity: a narrative review. Community Dent Health. 2014;31(1):15-20.

3: Orchardson R, Gillam DG. Managing dentin hypersensitivity. The Journal of the American Dental Association. 2006;137(7):990-8.

4: Vieira A, Santiago SL. Management of dentinal hypersensitivity. Gen Dent. 2009;57(2):120-6.

5: Sgan-Cohen HD, Livny A, Vered Y. The elmex SENSITIVE toothbrush: effect on plaque reduction and subjective satisfaction after two months. The Journal of clinical dentistry. 2008;19(1):22-7.

6: Biagi R, Cossellu G, Sarcina M, Pizzamiglio IT, Farronato G. Laser-assisted treatment of dentinal hypersensitivity: a literature review. Annali di stomatologia. 2015;6(3-4):75.

7: Mojahedi M SM, Sadr S J, Mighani GH, Mir M. Principal and Practice of Diode Laser in Dentistry. Tehran: Royan Pazhouh Publication; 2015.

8: Tunér J B-KP. Low-Level Laser in Dentistry. In Principles and Practice of Laser Dentistry: Mosby Elsevier; 2011.

9: Kathuria V, Dhillon JK, Kalra G. Low level laser therapy: a panacea for oral maladies. Laser therapy. 2015;24(3):215-23.
10: Mir M, Mojahedi SM, Adalatkhah H, Tunér J, Shirani AM, et al. Evaluation of a Newly Developed Laser Pen as a Home Care Device for Pain Reduction of Recurrent Aphthous Stomatitis (Preliminary Study). International Journal of Clinical Medicine. 2015;6(01):19.

11: Tunér J, Hode L. It's all in the parameters: a critical analysis of some well-known negative studies on low-level laser therapy. Journal of clinical laser medicine \& surgery. 1998;16(5):245-8.

12: Miller S, Abalos E, Chamillard M, Ciapponi A, Colaci D, et al. Beyond too little, too late and too much, too soon: a pathway towards evidence-based, respectful maternity care worldwide. The Lancet. 2016;388(10056):2176-92.

13: Samadzadeh H SM, Moosavi Fatemi N , Vakilzadeh SH , Bastani P , Sepehram V, Nazari L. Guidelines on the fluoride therapy in IRAN: Golabgir Publication; 2016.

14: Heft M, Litaker M, Kopycka-Kedzierawski D, Meyerowitz C, Chonowski S, et al. Patient-Centered Dentinal Hypersensitivity Treatment Outcomes: Results from the National Dental PBRN. JDR Clinical \& Translational Research. 2018;3(1):7682.

15: Kopycka-Kedzierawski DT, Meyerowitz C, Litaker MS, Chonowski S, Heft MW, et al. Management of Dentin Hypersensitivity by National Dental Practice-Based Research Network practitioners: results from a questionnaire adminis- 
tered prior to initiation of a clinical study on this topic. BMC oral health. 2017;17(1):41.

16: Petersson LG. The role of fluoride in the preventive management of dentin hypersensitivity and root caries. Clinical Oral Investigations. 2013;17(1):63-71.

17: Asnaashari M, Moeini M. Effectiveness of lasers in the treatment of dentin hypersensitivity. Journal of lasers in medical sciences. 2013;4(1):1.

18: Gillam DG. Treatment approaches for dentin hypersensitivity. Clinician's Guide to the Diagnosis and management of Tooth Sensitivity: Springer; 2014. p. 51-79.

19: Blatz MB. Laser therapy may be better than topical desensitizing agents for treating dentin hypersensitivity. Journal of Evidence Based Dental Practice. 2012;12(2):69-70.

20: Honarmand M, Farhadmollashahi L, Vosoughirahbar E. Comparing the effect of diode laser against acyclovir cream for the treatment of herpes labialis. Journal of clinical and experimental dentistry. 2017;9(6):e729.

21: Albrektson M, Hedström L, Bergh H. Recurrent aphthous stomatitis and pain management with low-level laser therapy: a randomized controlled trial. Oral surgery, oral medicine, oral pathology and oral radiology. 2014;117(5):590-4.

22: Petrović M, Kannosh I, Milašin J, Mihailović D, Obradović R, et al. Clinical, microbiological and cytomorphometric evaluation of low-level laser therapy as an adjunct to periodontal therapy in patients with chronic periodontitis. International journal of dental hygiene. 2018;16(2):e120-e7.

23: Dantas EM, Amorim FKdO, Nóbrega FJdO, Dantas PMC, Vasconcelos RG, et al. Clinical efficacy of fluoride varnish and low-level laser radiation in treating dentin hypersensitivity. Brazilian dental journal. 2016;27(1):79-82.

24: Corona SAM, Nascimento Td, Catirse A, Lizarelli R, Dinelli $\mathrm{W}$, et al. Clinical evaluation of low-level laser therapy and fluoride varnish for treating cervical dentinal hypersensitivity. Journal of Oral Rehabilitation. 2003;30(12):1183-9.

25: Doshi S, Jain S, Hegde R. Effect of low-level laser therapy in reducing dentinal hypersensitivity and pain following periodontal flap surgery. Photomedicine and laser surgery. 2014;32(12):700-6.

26: Ko Y, Park J, Kim C, Park J, Baek S, et al. Treatment of dentin hypersensitivity with a low-level laser-emitting toothbrush: double-blind randomised clinical trial of efficacy and safety. Journal of oral rehabilitation. 2014;41(7):523-31.

27: Yaghini J, Mogharehabed A, Safavi N, Mohamadi M, Ashtiju F. Evaluation of the effect of low level laser therapy toothbrush in treatment of dentin hypersensitivity. Journal of lasers in medical sciences. 2015;6(2):85.

28: Pesevska S, Nakova M, Ivanovski K, Angelov N, Kesic L, et al. Dentinal hypersensitivity following scaling and root planing: comparison of low-level laser and topical fluoride treatment. Lasers in medical science. 2010;25(5):647-50.

\section{Funding disclosure}

This work was supported by the research committee of Ardabil University of Medical Sciences (grant No. 90368).

\section{Acknowledgments}

The authors gratefully acknowledge the financial support provided by the research committee of the Ardabil University of Medical Sciences. The authors also appreciate the assistance of Dr. R. Masoudi from Laser and Plasma Research Institute of Shahid Beheshti University.

\section{Author disclosure}

The authors do not have any conflicts of interest to disclose. 